
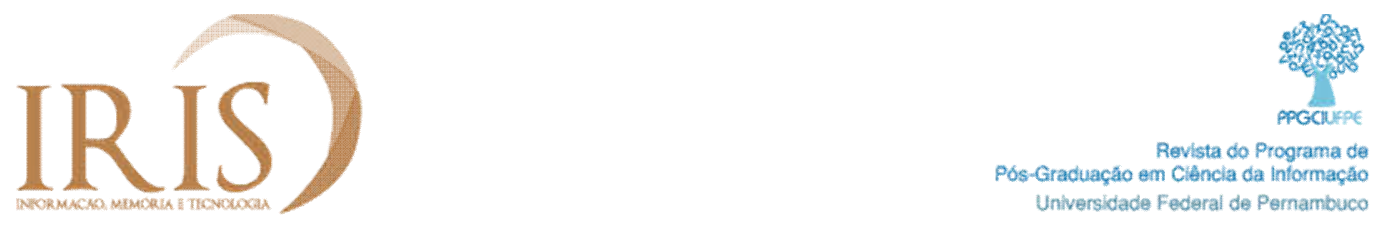

\title{
Frevo em Cordel: uma análise do Acervo da Fundação Casa de Rui Barbosa
}

\section{Frevo in Cordel: an analysis of the collection of the Rui Barbosa' house Foundation}

\author{
Vânia Ferreira da Silva \\ Bibliotecária da Universidade Federal Rural de Pernambuco (UFRPE) \\ Doutora em Educação em Ciências pela Universidade Federal do Rio Grande do Sul (UFRGS)
}

\author{
Andréa Carla Melo Marinho \\ Bibliotecária da Universidade Federal de Pernambuco (UFPE) \\ Doutora em Comunicação e Informação pela Universidade Federal do Rio Grande do Sul (UFRGS)
}

Vildeane da Rocha Borba

Professora do Departamento de Ciência da Informação da Universidade Federal de Pernambuco (UFPE)

Doutora em Comunicação e Informação pela Universidade Federal do Rio Grande do Sul (UFRGS)

\begin{abstract}
Resumo: Analisa o termo frevo em folhetos de cordel, compreendendo o seu uso e significado e refletindo de que forma dialogam entre si. De cunho qualiquanti, do tipo descritiva, utilizou como técnica de coleta de dados a análise de conteúdo e a entrevista semiestruturada. Foram analisados 14 folhetos de cordel dos quais apresentaram o termo frevo com o sentido de Bagunça, Festa (Baile, Celebração e Farra) e Expressão cultural. O sentido de bagunça remete a época a qual a cidade Recife se encontrava, inspirada principalmente pelos ideais abolicionistas; a relação com Festa, subdividida em Baile alude a dança, celebração denota comemoração de eventos e Farra revela a brincadeira. Já a significância de expressão cultural sugere as manifestações da dança, música, troça, fanfarras retratando ao frevo propriamente dito. Acredita-se que este trabalho contribui para a Ciência da Informação a partir das práticas culturais, compreendendo como os grupos sociais tecem seus saberes e, sobretudo, por meio da Ciência da Informação podemos comunicar e visualizar esse conhecimento, identificando, estudando e refletindo também sobre as fontes de informação marginalizadas.
\end{abstract}

Palavras-chave: Frevo. Literatura de Cordel. Cultura. Expressão cultural.

Abstract: It analyzes the term frevo in folhetos de cordel, understanding its use and meaning and reflecting how they dialogue with each other. Qualiquanti, descriptive type, used as data collection technique the content analysis and semi-structured interview. Fourteen folhetos de cordel were analyzed from which they presented the term frevo with the meaning of Mess, Party (prom, Celebration and Spree) and Cultural Expression. The sense of mess goes back to the time the city of Recife was, inspired mainly by the abolitionist ideals; the relationship with party, subdivided in prom alludes to dance, celebration denotes celebration of events and spree reveals the joke. Already the significance of cultural expression suggests the manifestations of dance, music, troça, fanfara portraying the frevo itself. It is believed that this work contributes to Information Science from cultural practices, understanding how social groups weave their 
knowledge and, above all, through Information Science we can communicate and visualize this knowledge, identifying, studying and also reflecting on marginalized sources of information.

Keywords: Frevo. Literatura de Cordel. Culture. cultural expression.

\section{Introdução}

O cordel ao longo dos tempos vem divertindo e informando seus leitores e ouvintes. No Brasil essa literatura tem um diálogo forte com o povo, e é nos mercados, ruas e praças que os poetas declamam sua poesia e fazem a diversão. O poeta por sua vez, além de divertir, em alguns casos toma para si o papel de repórter. Eles registram fatos do seu tempo, se apropriam das notícias dos jornais e rádio da época para, através da sua poesia, informar fatos aos leitores.

A literatura popular ao chegar ao Brasil traçou sua própria roupagem, ganhando principalmente no meio rural um forte diálogo com a história nacional e os acontecimentos cotidianos de cada povoado. Cascudo (1984, p. 236) afirma que "o conto popular revela informação histórica, etnográfica, sociológica, jurídica e social", tornando-se um documento vivo, quando relata os "[...] costumes, ideias, mentalidades, decisões, e julgamentos".

A literatura de cordel é uma poesia popular muito presente no Nordeste do Brasil e segundo Abreu (1993), nos séculos XVIII e XIX houve um envio dos cordéis portugueses para o Brasil, mas o cordel brasileiro apresenta características diferentes quanto à forma, produção e circulação, tendo a primeira geração de cordelistas no Brasil dedicados a escrita do tipo de folheto de romance ou história.

Além da literatura de cordel dedicada ao romance ou história, há um segundo tipo de cordel denominado como circunstancial ou de acontecido, que se dedicava aos acontecimentos da época, também chamado de cordéis informativos (CURRAN, 2001). Nesse contexto, o frevo originado no cenário da colonização escrava do Nordeste brasileiro, tendo diversos passos derivados da capoeira, refletiu do ponto de vista social, como uma grande expressão musical popular.

Frevo de rua, Frevo de bloco ou Frevo canção, contemplam o registro da cultura musical de Pernambuco em uma das comemorações mais populares no Brasil, o carnaval, tendo sua representatividade em Pernambuco revelada através da música, da dança, das fantasias, estandartes, brincadeiras, diversão carregando uma identidade e manifestação cultural popular singular. 


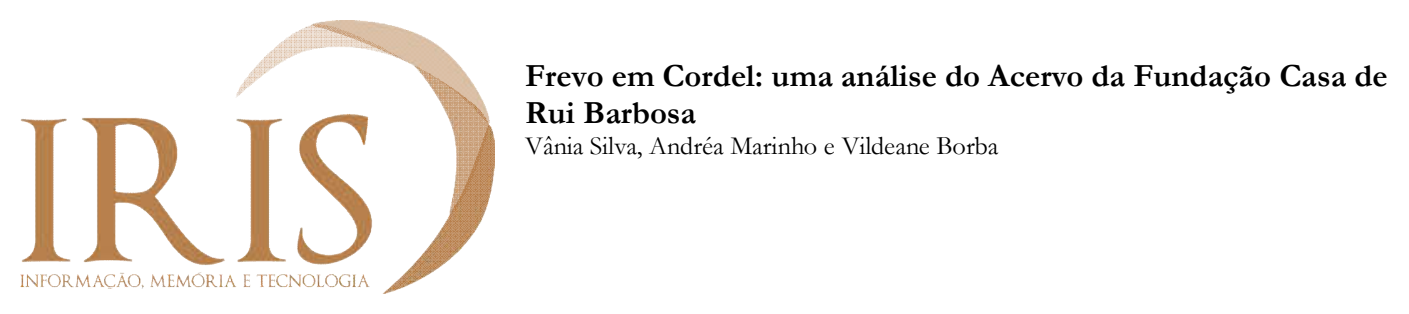

Diante do exposto e visualizando o frevo como uma manifestação popular, este trabalho objetivou analisar o termo frevo em folhetos de cordéis, compreendendo o seu uso e significado ao longo dessa produção literária, visto que essa literatura escrita se desenvolveu a partir de 1930 em grandes tipografias no Nordeste, e sua atuação mais forte deu-se em Pernambuco e na Paraíba.

Ao analisar o cordel como fonte de informação, entende-se seu valor como documento, memória registrada através da poesia e em especial no cordel de circunstância que retrata a busca por notícia, por uma poética que informa e registra a memória da época. Nessa reflexão sobre o cordel como poesia e memória escrita e cultural de um povo, buscou-se refletir sobre a relação com o frevo, manifestações culturais tão presentes na história de Pernambuco, e de que forma elas dialogam entre si.

Neste contexto, estudar o cordel em Pernambuco é contribuir para traçar a memória social de grupos populares, artistas da cultura popular e seu modo de narrar os fatos da época. E, nessa perspectiva, entender como esses poetas utilizaram a informação a fim de produzir seus cordéis e sua relação com o frevo é importante para inseri-lo num ponto de vista de fonte de informação e estudo para a Ciência da Informação.

\section{Cordel e frevo}

Desvendando expressões artísticas oriundas do povo e para o povo, este trabalho buscou relacionar o frevo e a literatura de cordel, tentando vislumbrar o encantamento de artes que tiveram o seio do povo como sua raiz propulsora, inovadora e criativa. A literatura de cordel é uma poesia popular com forte influência no Nordeste do Brasil. De possível origem européia foi no Nordeste que o cordel teve maior representatividade em que a poesia popular gerou uma motivação e logo se tornou um aliado do povo, para divulgar seus anseios, medos e alegrias, sentimentos expressos e compreendidos devido a uma tipologia de linguagem comum, simples e acessível à cultura nordestina. Na primeira geração de poetas, divisão elaborada pela fundação Casa de Rui Barbosa é possível identificar a influência desses poetas no que diz respeito à formação do público.

Aos poetas da primeira geração, além da constituição do público e do estabelecimento das formas de produção e distribuição da literatura de cordel, coube também o papel de definir as regras do gênero criando os estilos e temas que a distinguiriam da literatura tradicional oral da qual, por sua vez, a poesia popular impressa teria tomado de empréstimo vários 


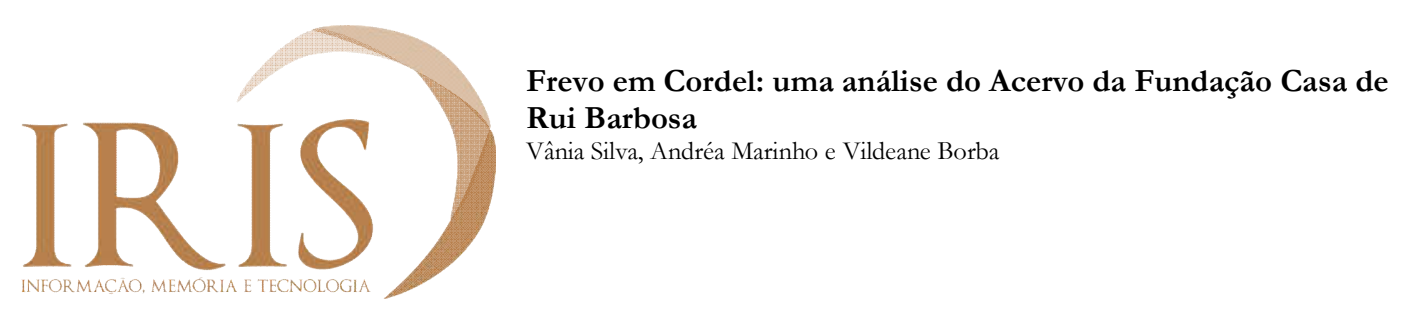

elementos, entre os quais a sua própria forma de transmissão cuja base oral se traduz, principalmente, na estrutura metrificada e rimada que lhe é característica (FUNDAÇÃO CASA DE RUI BARBOSA, [20-?]).

O cordel foi classificado por alguns autores, como Ariano Suassuna e Liêdo Maranhão, que propuseram algumas divisões para essa literatura popular e que contribuíram para outros estudos como o de Curran. Curran (2001) de forma simples, divide o cordel em dois tipos, que são: os longos poemas narrativos denominados "romances" ou "histórias" que tinham em torno de 32 a 64 páginas, que se destinavam a falar sobre amores, sofrimentos ou aventuras, motivados por um discurso heroico de ficção; e o segundo que é a poesia circunstancial ou de acontecido que se destinava a noticiar fatos e a história do povo.

É importante ressaltar que essa literatura popular é formada por um público que em sua grande maioria não era letrado, que utilizava-se do cordel como uma expressão cultural que podia levá-los ao mundo fantástico das histórias longas e heroicas e que podiam informar, trazer notícias e fatos da época em que viviam e que por muitas vezes por sua falta de leitura ou acesso a meios de comunicação caros como o rádio não tinha acesso.

O cordel como poesia popular se desenvolve no meio do povo do nordeste para falar desse povo, da sua cultura e da sua história. Curran, um pesquisador sobre a literatura de cordel, relata que:

O que o cordel me ensinou a respeito do Brasil? Aprendi sobre seu povo, através de um elenco de personagens tanto humildes quanto nobres do Nordeste do país, mas também sobre a própria Nação. Os eventos do século XX ficavam espalhados à minha frente, em centenas de livrinho de versos, que relatavam desde pequenos fatos aparentemente insignificantes da vida nordestina, seja da vila do interior, seja das cidades costeiras importantes, até os principais eventos nacionais e alguns internacionais (CURRAN, 2001, p. 12).

$\mathrm{Na}$ década de 70 e 80 o cordel vira moda para uma parte da classe média e alta do Brasil, e através desse interesse por parte dos intelectuais o cordel atingiu um destaque ganhando espaço e identificando-se como herança cultural, no que diz respeito ao registro da cultura de um povo, a informação e formação de leitores, pois muitos nordestinos aprenderam a ler através das estrofes dessa poesia tão popular. Estudar o cordel como literatura é descobrir que além de sua vertente poética, ele divertiu, informou e formou a gerações de nordestinos que tinha nessa literatura uma ligação de identidade e pertencimento, o cordel deu voz e vez ao povo nordestino.

Não obstante, a presença da palavra frevo no cordel vai além do registro formal de uma temática, ela introduz como essa manifestação artística era vista pelos poetas e pelo povo. Os 


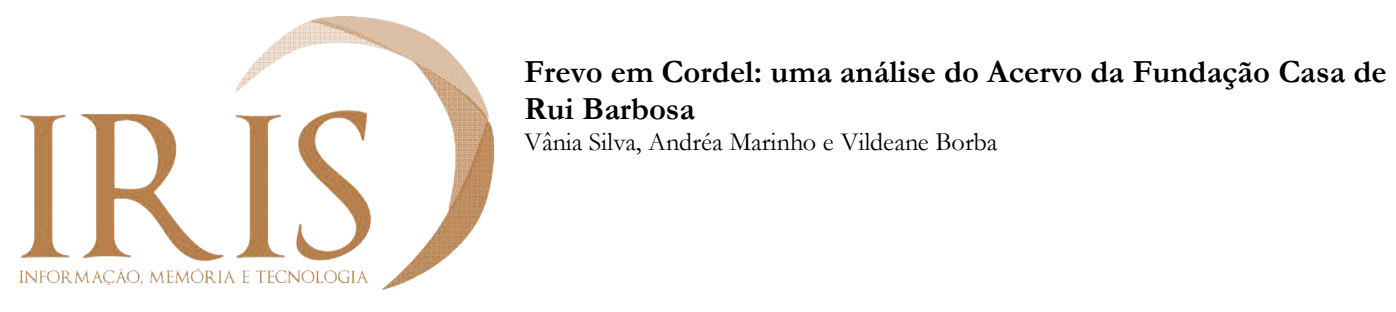

primeiros indícios do que seria um bloco de frevo surge no século XVIII tendo como brincantes os trabalhadores negros do bairro portuário do Recife. (BARBOSA, 2016).

A palavra frevo - corruptela do verbo ferver -, a princípio, relacionava-se mais ao contexto sociocultural e político vivido nas ruas do Recife no final do século XIX. Nessa época, a cidade revelava a agitação e a rebeldia insufladas pelos ideais nacionalistas, republicanos e abolicionistas (BARBOSA, 2016).

Recife estava vivendo um momento de ebulição com a abolição da escravatura, a modernização e a constituição das classes trabalhadoras e é nesse contexto que o frevo surge como uma manifestação de resistência do povo, dos trabalhadores negros e como uma música urbana (BARBOSA, 2016).

Compreender o frevo é, de certa forma, reconstituir parte da história das camadas populares e da própria formação da cidade do Recife, de fins do século XIX e início do século XX. Manifestação que se criou no meio do povo e afirma-se, depois, como traço marcante de sua fisionomia urbana. (BARBOSA, 2016).

O frevo é uma manifestação do carnaval, ele surge nas vias urbanas e da vontade de um povo de resistir as intempéries da vida, de ser brincante e de lutar por seu espaço de luta e fala. As expressões carnavalescas do frevo se materializam na música, dança, estética e roupas, que estão relacionadas respectivamente com o catolicismo, a capoeira, os estandartes (bandeiras dos santos católicos) e a herança portuguesa e da elite pernambucana.

A música é experimentada e difundida por militares, apesar de ser uma música popular e se desenvolver com mais intensidade no século XX por meio dos blocos carnavalescos na cidade de Recife. De acordo com Menezes e Nascimento (2011, p. 17), a musicalidade que iria dar origem ao frevo surge, segundo muitas evidências, do processo de hibridização musical semelhante aos identificados em outros lugares do Brasil (como no caso do choro no Rio de Janeiro) e das Américas.

O termo frevo surge como manifestação popular do Recife, que se deu num processo de disputa/conflitos, inclusive entre os grupos carnavalescos (São José, Santo Antônio, Boa Vista) e também no contexto político.

O primeiro registro da palavra apareceu em letra de forma no Jornal Pequeno, editado em 9 de fevereiro de 1907, quando foi publicado o repertório do clube carnavalesco Empalhadores do Feitosa que constava a marcha $\mathrm{O}$ frevo. A expressão já era comum nas ruas, corruptela do verbo ferver, pronunciada popularmente frever. Com o tempo designa um gênero musical, impresso nas partituras e nos selos dos discos (MENEZES; NASCIMENTO, 2011, p. 17). 


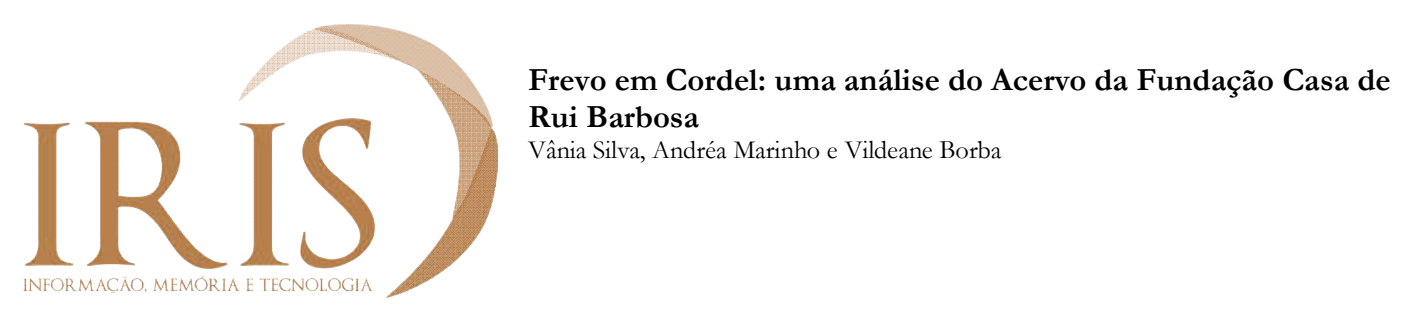

No tocante a sua manifestação, o frevo se apresenta sob diversas denominações tais como dobrado, marcha, marcha carnavalesca, marcha pernambucana, marcha nortista, marcha-frevo, marcha-polca ou polca-marcha. No início do século XX, compositores como Capiba, Levino Ferreira e Nelson Ferreira solidificam o formato musical específico dos frevos instrumentais e cantados, e a partir da década de 1930, com a popularização do ritmo pelas gravações em disco e pela difusão radiofônica, consagrou-se a subdivisão estabelecida atualmente como: frevo de rua, frevo-canção e frevo de bloco.

\section{Metodologia}

Trata-se de pesquisa de caráter qualiquanti, do tipo descritiva, que utilizou como técnica de coleta de dados a análise de conteúdo e entrevista semiestruturada, e teve como objeto de estudo os folhetos de cordéis que apresentaram o termo frevo em sua estrutura (BARDIN, 2016; MICHEL, 2009).

As etapas metodológicas compreenderam: a) levantamento de folhetos de cordéis, b) análise de conteúdo dos cordéis recuperados, c) Desenvolvimento de categorização temática e d) Entrevista semiestruturada.

O Levantamento de folhetos de cordéis foi realizado em abril de 2017 a partir do acervo da Fundação Casa de Rui Barbosa ${ }^{1}$ que apresenta mais de 2.340 folhetos em formato digital e a mesma foi escolhida como fonte de informação por ser considerada o espaço que possui o maior acervo de Literatura Popular em versos da América Latina, com mais de 8.000 folhetos de cordel, destes aproximadamente $29 \%$, disponível em meio digital.

O termo de busca utilizado para recuperação de informação na base de dados foi "frevo", sendo recuperados 18 folhetos de cordéis, abrangendo seis diferentes poetas, todos da segunda geração, são eles: Francisco Sales Arêda, João Martins de Ataíde, José Pacheco, José Soares, Minelvino Francisco Silva e Rodolfo Coelho Cavalcanti.

Os folhetos de cordel foram analisados individualmente, e quatro folhetos dos 18 encontrados não possuíam o termo frevo e a base de dados estava recuperando o termo "freud". Além do termo "frevo", foram pesquisados os termos "frevança", "frevar", "ferver" e "frever", não obtendo resultados. Neste sentido, a análise de conteúdo foi realizada em 14 folhetos. 


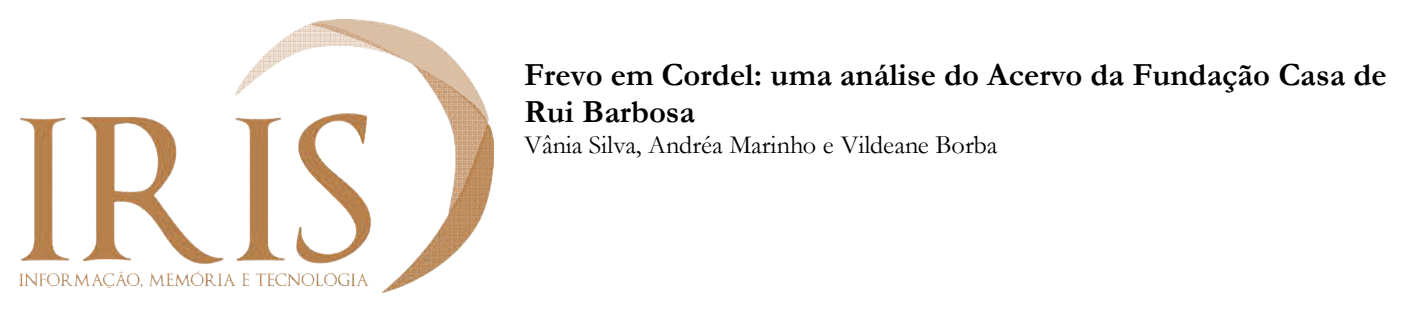

A análise de conteúdo dos 14 cordéis recuperados foi realizada a partir da leitura dos folhetos, extração e frequência dos termos relacionados com o frevo por cordel, totalizando 39 termos relacionados, dos quais os termos "dança" e "bagunça" apresentaram as maiores frequências com quatro e três ocorrências respectivamente. Consequentemente, os termos relacionados deram suporte para o desenvolvimento da categorização temática, abrangendo cinco categorias, sendo elas: Expressão cultural ( $n=5)$, Festa - Celebração $(n=3)$, Confusão $(n=2)$, Festa - baile $(n=2)$ e Festa Farra $(n=2)$, tendo a categoria Expressão cultural a maior ocorrência.

A entrevista semiestruturada foi realizada no Paço do Frevo situado na Praça do Arsenal, no Recife Antigo, Pernambuco em 5 de maio de 2017, com a bibliotecária e assistente de Documentação e memória e o historiador e assistente de pesquisa do Paço do Frevo e foi utilizada para referencial da análise e discussão dos dados.

\section{Análise e discussão dos dados}

Os folhetos de cordel analisados estão organizados conforme a produção de cada poeta, como mostra o Quadro 1. Os mesmos são naturais de quatro estados do Nordeste: Alagoas, Bahia, Paraíba e Pernambuco. Dos 14 cordéis encontrados, nenhum possui o termo frevo descrito no título, entretanto dois folhetos possuem o termo carnaval.

Quadro 1 - Descrição de Poetas e Títulos de Cordéis

\begin{tabular}{|c|c|}
\hline POETA & TÍTULO DOS CORDÉIS \\
\hline \multirow{2}{*}{ Francisco Sales Arêda } & Um aviso de Frei Damião e os sinais do fim dos tempos \\
\hline & O Romance de João Bêsta com a jia da lagoa \\
\hline \multirow{3}{*}{ João Martins de Ataíde } & O Amor de uma estudante ou o poder da inteligência \\
\hline & O Homem que subiu em aeroplano até a lua \\
\hline & A vida de Nascimento grande o homem do pulso de ferro \\
\hline José Pacheco & Mulher no lugar do homem \\
\hline \multirow{2}{*}{ José Soares } & O leão tirou a titica, campeão 77 \\
\hline & A perna cabeluda de Tiuma e São Lourenço \\
\hline Minelvino Francisco Silva & $\begin{array}{l}\text { A moça que namorou com o diabo nos três dias de carnaval } \\
\text { pensando ser Roberto Carlos }\end{array}$ \\
\hline \multirow{5}{*}{ Rodolfo Coelho Cavalcanti } & ABC de Mário Filho \\
\hline & O Drama do comandante \\
\hline & História da moça que virou cavalo \\
\hline & Maceió do tempo do major Bonifácio \\
\hline & Que se ver no carnaval \\
\hline
\end{tabular}

Fonte: Dados de pesquisa, 2019. 


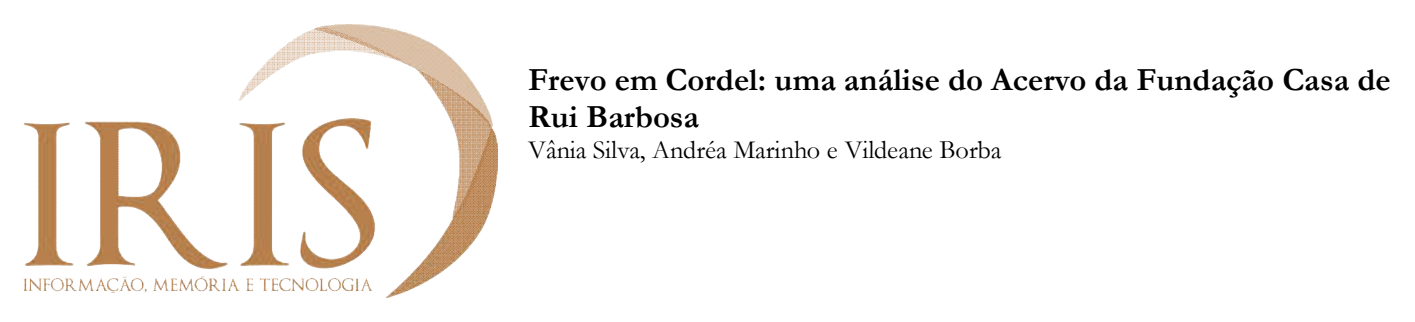

\subsection{Análise do termo frevo nos cordéis}

De acordo com o Quadro 1, organizado por ordem alfabética de autores, o primeiro poeta a ser analisado é Francisco Sales Arêda (1916), natural de Campina Grande (PB), mudando-se para Caruaru em 1927. O folheto do cordelista "Um aviso de Frei Damião e os sinais do fim dos tempos", relata temas como corrupção, práticas sociais, religião e moralismo, tendo o termo frevo neste cordel relacionado à festa, diversão e bagunça. Segundo Curran (2011), na produção de cordel brasileira, são recorrentes as temáticas sobre moralidade e religiosidade.

O cordel "O Romance de João Bêsta com a jia da lagoa", trata de um conto que narra a história de três irmãos que saem de casa em busca de fazer suas vidas, apresentando um viés moralista a respeito da ganância a partir da relação entre pais e filhos, tendo o termo frevo no contexto desse cordel representado à festa, diversão e celebração.

O segundo poeta João Martins de Ataíde, natural de Cachoeiras de Cebola (PB) migra para Pernambuco em 1898 devido à seca e falece em Limoeiro (PE) em 1959. Foram encontrados de sua autoria, três cordéis com a ocorrência do termo frevo, entre eles "O Amor de uma estudante ou o poder da inteligência", um romance que trata sobre a história de um casal e suas duas filhas, apresentando um contraponto entre beleza e inteligência, mostrando a palavra frevo com sentido de bagunça.

O cordel "O Homem que subiu em aeroplano até a lua" é um conto que aborda sobre a estória de Baratão que vai à lua em seu aeroplano e lá se apaixona por uma princesa. O termo frevo, que aparece mais de uma vez, está ligado a uma comemoração festiva, celebração, neste caso o casamento. Percebe-se que quando o termo frevo está relacionado à comemoração festiva, há uma ocorrência de outros termos como balão, bomba, buscapé, foguetes, folguedos, giranda e girandola.

No último cordel de José Martins de Athaíde, “A vida de Nascimento grande: o homem do pulso de ferro", o termo frevo aparece no texto com sentido de confusão e bagunça. Na história de Nascimento, um homem valente, o cordel mostra suas aventuras e lutas diárias em defesa da honra e segurança do povo. Curran (2011, p. 130) diz que: Outra variante do cordel trata do sertanejo valente, herói de centenas de poemas. É um verdadeiro herói nordestino com os atributos do herói tradicional, já visto nos romances de cordel. Percebe-se que a história de Nascimento é uma variante 


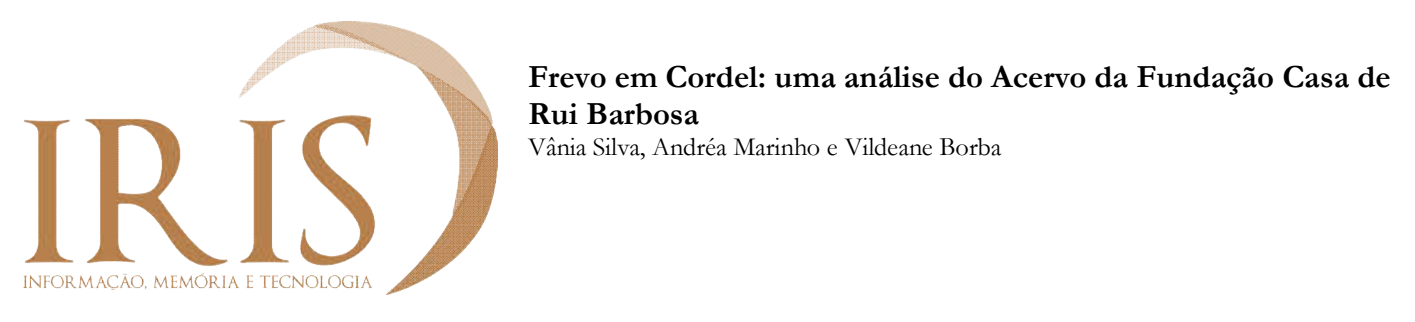

desse tipo de Cordel relatado por Curran (2011) que traça o perfil de um herói do cotidiano, com sua valentia e histórias.

O poeta José Pacheco nasceu no Município de Corrientes (PE), residiu algum tempo em Caruaru, depois se mudou para Alagoas vivendo nessa cidade até falecer em 1954. Seu cordel "Mulher no lugar do homem" é um relato da mudança das atividades das mulheres no mercado de trabalho e apresenta um discurso machista usual no tempo do poeta. Neste folheto, foi utilizado o vocábulo "vai a frevo" e em entrevista com a bibliotecária e assistente de Documentação e memória do Paço do Frevo, a expressão “vai a frevo" está relacionada ao sentido de festa. Silva (2017) diz que: "Porque frevo era freje. Freje é um tipo de festa, agito. Freje podia ser confusão também, a reunião de pessoas. E frevo vem nesse sentido também de ebulição. Frevo vem associado ao freje. Antigamente, a mulher não estava presente no frevo na rua, tanto é que foram criados os blocos líricos mistos no intuito de inserir a mulher onde ela era antes julgada, caso ela estivesse, isso no início do século passado".

Curran (2011) faz algumas reflexões sobre a presença da figura feminina moderna e a difícil aceitação do poeta e seu público, que ainda apresenta uma visão paternalista com princípios religiosos e morais da velha igreja.

José Soares nascido em Alagoa Grande (PB) em 1914, ainda menino se encanta com os folhetos vendidos na feira, tendo sua biografa relatos de viagem ao Rio de Janeiro e em 1940 volta para Recife quando monta uma banca de folhetos no oitão do Mercado de São José. Foram encontrados dois cordéis do poeta com o termo frevo, um relacionado ao futebol, tema do qual gostava muito de escrever e outro sobre uma lenda urbana de Pernambuco.

O cordel "O leão tirou a titica, campeão 77" trata da vitória do campeonato pernambucano de 1977. Embora o poeta fosse tricolor, enaltece a vitória do Sport, time adversário, desempenhando bem seu papel de poeta-repórter. Curran (2011, p. 201) diz que “o cordel apresentava fatos e notícias do dia como se fosse o jornal do povo". Além disso, o autor menciona que alguns cordelistas tornaram-se poetas-repórteres, com destaque para José Soares em Recife. O cordel “A perna cabeluda de Tiúma e São Lourenço" trata de uma lenda urbana pernambucana. O termo frevo aparece como dança, relacionado com os termos xaxado e sanfoneiro, que também são associados à dança.

Minelvino Francisco Silva nasceu no povoado de Palmeiral, Município de Mundo Novo (BA) e radicou-se em Itabuna (BA), vivendo intensamente no mundo do cordel, sendo xilógrafo 


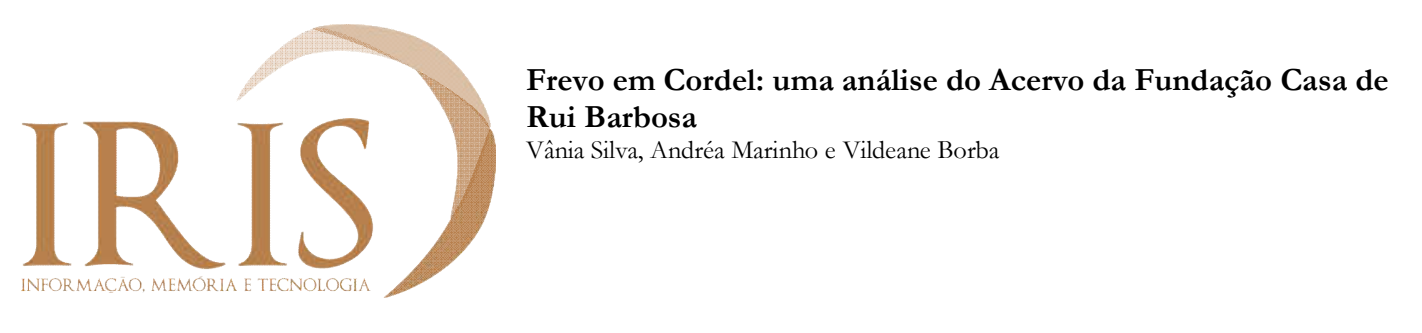

talentoso e participado de alguns concursos de cordel. No cordel "A moça que namorou com o diabo nos três dias de carnaval pensando ser Roberto Carlos" conta a estória, ocorrida na Bahia, de uma moça que queria brincar carnaval contra a vontade de seu pai, tendo o termo frevo como manifestação cultural, dança, orquestra e música. É importante ressaltar que na estrofe o poeta diz que a moça:

Dançava e cantava alto

Dando pulos para o ar

Enfatiza-se que é a primeira vez que o termo frevo aparece com uma conotação forte de dança, apresentando os passos referentes à essa manifestação cultural. Além de o cordel apresentar um forte cunho moralista, uma vez que enfatiza a desobediência da moça, ele também traz à tona reflexões levantadas por Curran (2011, p. 47):

Foi, portanto, a junção de vários fenômenos sem qualquer relação entre si que criou uma situação que renderia milhares de poemas de cordel sobre o tema: a loucura pelo rock in roll e por Roberto Carlos, a tradição do cordel em sim, o papel do diabo na religião popular brasileira, e o encontro inesperado dos três.

Esse cordel relata bem essa junção dos três fatores, pois Curran (2011) relata que esse fenômeno se deu pelo lançamento da música "Quero que vá tudo para o inferno". A figura de Roberto Carlos começou a ser vinculada a rebeldia dos jovens.

Rodolfo Coelho Cavalcanti natural do Rio Largo (AL) em 1919 vai morar em Salvador (BA) em 1945 e na Bahia, realiza o I Congresso Nacional de Trovadores e Violeiros, fundando também alguns periódicos na área. O cordel "ABC de Mário Filho" trata de uma homenagem ao radialista Mário Filho que apresentava o programa "Recordar é viver" que enaltecia a cultura pernambucana. O radialista era pernambucano e irmão do jornalista e escritor Nelson Rodrigues, tendo o frevo nessa poesia popular retratado como ritmo musical, atrelado a outros gêneros comentados na estrofe como: Xaxado, samba, baião, tango argentino, quadrilha, valsa, xote e chula.

"O Drama do comandante" apresenta um drama sobre traição, vingança, crime passional, maus tratos maternos, amizade e lealdade entre patrão e empregado. Nesse contexto aparece a expressão "Frevo na casa de Noca", que denota um sentido de festa. Segundo Dicionário Informal online (c2006-2017), casa de Noca é uma casa que todos mandam, não tem dono, nem governança. É uma casa bagunçada. 


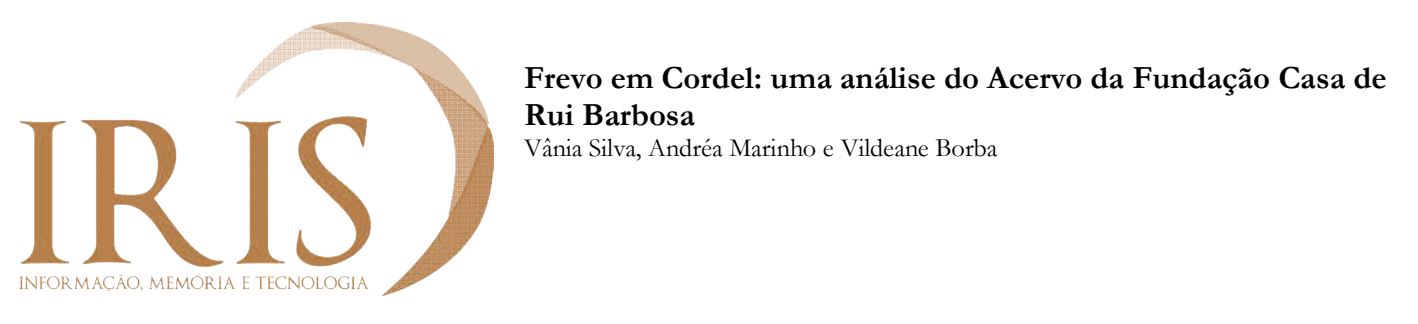

O cordel "História da moça que virou cavalo" relata estória da mulher que virou cavalo, após desobedecer a mãe que pedia para ela não ir para festa de carnaval. O termo frevo aparece com sentido de festa, carnaval e folia. "Maceió do tempo do major Bonifácio" relata a história de Major Bonifácio, outros ícones da cultura local de Maceió e suas manifestações. O termo frevo aparece como dança, ginga e malícia. O poeta faz também uma importante relação com a capoeira, dizendo que um dos personagens era bom no frevo e rei da capoeira, sendo um cordel que conta fatos e relata a memória da sociedade em Alagoas, dos personagens e da vida como era naquele tempo. "Que se ver no carnaval" é um cordel que apresenta o carnaval como uma festa profana e sem valores éticos e culturais. O termo frevo aparece como manifestação cultural, dança e música.

O poeta Rodolfo Coelho Cavalcanti é o que mais escreve em seus folhetos sobre o frevo, encontrado em cinco deles. O interessante é que além de escrever mais sobre o tema, ele também apresenta o frevo como dança ou manifestação cultural, chega a relatar o frevo como dança e como música, e por vezes em alguns cordéis apresenta expressões como pulos ao ar e frevo do passo, além de fazer uma relação com a capoeira.

Percebeu-se que os 14 cordéis encontrados no acervo da Fundação Casa de Rui Barbosa com relação ao termo frevo, foram escritos por poetas da segunda geração, que compreende o período de produção entre 1920/1930. Os mesmos falam de carnaval como uma festa profana, com desvio de valores, bem relacionado à visão da igreja. Neste sentido, Curran (2011) evidenciou em seu livro Retratos do Brasil em Cordel uma visão moralista, religiosa e muito ligada ao perfil paternalista e autoritário do homem da época, um perfil também adotado pelos poetas no seu tempo.

Luyten (200?) em outras palavras, enquanto a Literatura de Cordel se ativer essencialmente a seu público tradicional, que tem por referência um mundo regido pelo ciclo agropecuário, o domínio do elemento masculino é praticamente inconteste e todos os valores, inclusive as exceções, são ditados por essa visão de realidade. Não pretende-se entrar no mérito da discussão sobre preconceito ou machismo, mas evidenciar a postura dos cordelistas dessa época que eram regidos por esse tipo de pensamento e valores que estava presente em suas obras, tanto por ser uma visão do poeta como para agradar o seu público que partilhavam desse pensamento.

\subsection{Categorização do Termo Frevo nos Cordéis}


IRIS

Frevo em Cordel: uma análise do Acervo da Fundação Casa de

Rui Barbosa

Vânia Silva, Andréa Marinho e Vildeane Borba

Encontrou-se o termo frevo relacionado com bagunça em três cordéis dos 14 encontrados no acervo da Fundação Casa de Rui Barbosa, dos quais os poetas Francisco Sales de Arêda (1916), João Martins de Athaíde (1980) e José Pacheco (1890) se inserem e os mesmos nasceram no século XIX quando a palavra frevo ainda não tinha o sentido de expressão cultural que tem nos dias de hoje.

\begin{tabular}{|c|c|c|}
\hline TÍTULOS & $\begin{array}{c}\text { TERMOS } \\
\text { RELACIONADOS }\end{array}$ & CATEGORIZAÇÃO \\
\hline $\begin{array}{l}\text { Um aviso de Frei } \\
\text { Damião e os sinais } \\
\text { do fim dos tempos }\end{array}$ & $\begin{array}{l}\text { Discoteque } \\
\text { Diversão } \\
\text { Bagunça } \\
\text { Anarquia }\end{array}$ & Festa (baile) \\
\hline $\begin{array}{l}\text { O Romance de } \\
\text { João Bêsta com a } \\
\text { jia da lagoa }\end{array}$ & $\begin{array}{l}\text { Diversão } \\
\text { Celebração } \\
\text { Cortejo animado }\end{array}$ & $\begin{array}{l}\text { Festa } \\
\text { (Celebração) }\end{array}$ \\
\hline $\begin{array}{l}\text { O Amor de uma } \\
\text { estudante ou o } \\
\text { poder da inteligência }\end{array}$ & $\begin{array}{l}\text { Bagunça } \\
\text { Anarquia } \\
\text { Deboche }\end{array}$ & Confusão \\
\hline $\begin{array}{l}\text { O Homem que } \\
\text { subiu em } \\
\text { aeroplano até a lua }\end{array}$ & $\begin{array}{l}\text { Banquete } \\
\text { Folguedos } \\
\text { Foguete } \\
\text { Girandólas } \\
\text { Buscapé } \\
\text { Bomba }\end{array}$ & $\begin{array}{l}\text { Festa } \\
\text { (Celebração) }\end{array}$ \\
\hline $\begin{array}{l}\text { A vida de } \\
\text { Nascimento } \\
\text { grande o homem } \\
\text { do pulso de ferro }\end{array}$ & $\begin{array}{l}\text { Bagunça } \\
\text { Atacado } \\
\text { Vagabundo }\end{array}$ & Confusão \\
\hline $\begin{array}{l}\text { Mulher no lugar } \\
\text { do homem }\end{array}$ & Raco-raco & Festa (Farra) \\
\hline $\begin{array}{l}\text { O leão tirou a } \\
\text { titica, campeão } 77\end{array}$ & $\begin{array}{l}\text { Foguete } \\
\text { Bomba } \\
\text { Giranda } \\
\text { Balão }\end{array}$ & $\begin{array}{l}\text { Festa } \\
\text { (Celebração) }\end{array}$ \\
\hline $\begin{array}{l}\text { A perna cabeluda } \\
\text { de Tiuma e São Lourenço }\end{array}$ & $\begin{array}{l}\text { Xaxado } \\
\text { Sanfoneiro }\end{array}$ & Festa (baile) \\
\hline
\end{tabular}




\section{IRIS}

Frevo em Cordel: uma análise do Acervo da Fundação Casa de

\begin{tabular}{|c|c|c|}
\hline $\begin{array}{l}\text { A moça que } \\
\text { namorou com o } \\
\text { diabo nos três dias } \\
\text { de carnaval } \\
\text { pensando ser } \\
\text { Roberto Carlos }\end{array}$ & $\begin{array}{l}\text { Dança } \\
\text { Música } \\
\text { Orquestra }\end{array}$ & $\begin{array}{l}\text { Expressão } \\
\text { cultural }\end{array}$ \\
\hline $\begin{array}{l}\text { ABC de Mário } \\
\text { Filho }\end{array}$ & $\begin{array}{l}\text { Xaxado } \\
\text { Samba } \\
\text { Baião } \\
\text { Tango } \\
\text { Quadrilha } \\
\text { Valsa } \\
\text { Xote } \\
\text { Chula }\end{array}$ & $\begin{array}{l}\text { Expressão } \\
\text { cultural }\end{array}$ \\
\hline $\begin{array}{l}\text { O Drama do } \\
\text { comandante }\end{array}$ & Dança & $\begin{array}{l}\text { Expressão } \\
\text { cultural }\end{array}$ \\
\hline $\begin{array}{l}\text { História da moça } \\
\text { que virou cavalo }\end{array}$ & $\begin{array}{l}\text { Carnaval } \\
\text { Orgia } \\
\text { Folia }\end{array}$ & Festa (Farra) \\
\hline $\begin{array}{l}\text { Maceió do tempo } \\
\text { do major Bonifácio }\end{array}$ & $\begin{array}{l}\text { Dança } \\
\text { Ginga } \\
\text { Malandragem } \\
\text { Passe } \\
\text { Samba } \\
\text { Capoeira }\end{array}$ & $\begin{array}{l}\text { Expressão } \\
\text { cultural }\end{array}$ \\
\hline $\begin{array}{l}\text { Que se ver no } \\
\text { carnaval }\end{array}$ & $\begin{array}{l}\text { Dança } \\
\text { Música } \\
\text { Brincar } \\
\text { Passo } \\
\text { Carnaval } \\
\end{array}$ & $\begin{array}{l}\text { Expressão } \\
\text { cultural }\end{array}$ \\
\hline
\end{tabular}

Fonte: Dados de pesquisa, 2019.

Em entrevista no dia 5 de maio, com o historiador e assistente de pesquisa do Paço do Frevo em Pernambuco, Santos (2017) diz que:

“Os sentidos da palavra frevo nos anos 20 e 30, na primeira metade do século XX, é porque no processo de formação do frevo, ele não surgiu como essa palavra, não era bem isso, a gente gosta sempre de dizer que existe uma sistemática de influência, uma rede de influências culturais que contribuem para formação do frevo e consolidação no século XX”. 


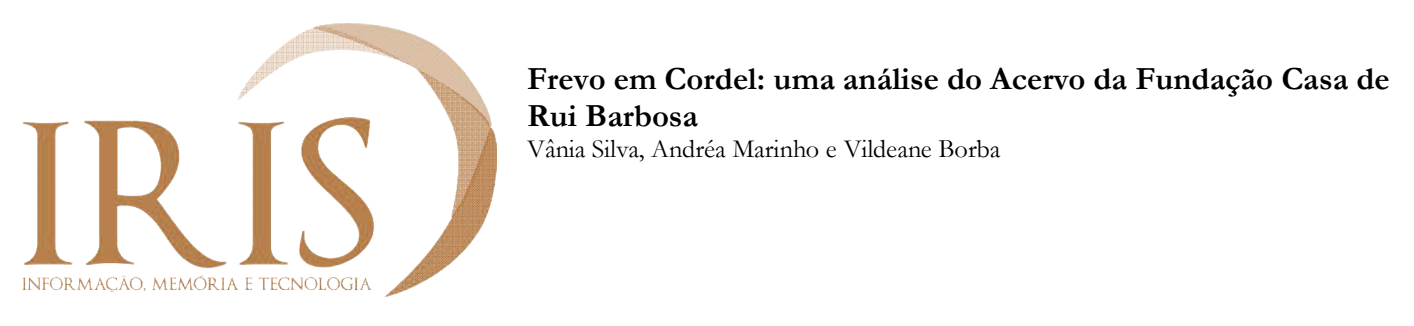

Ainda em pesquisa bibliográfica no Dossiê Iphan, o Frevo encontrava essas influências esclarecidas pelo historiador Luiz Henrique Costa. A palavra frevo, a princípio relacionava-se mais ao contexto sociocultural e político vivido nas ruas do Recife no final do século XIX. Nessa época a cidade revelava a agitação e a rebeldia insufladas pelos ideais nacionalistas, republicanos e abolicionistas. (BARBOSA, 2016, p. 13).

Diante desses fatos, é possível entender o contexto desses poetas que escreveram o termo frevo relacionado com bagunça, eles estavam vivenciando esses conflitos e o jornal da época utilizava o termo frevo também dessa forma como relata o historiador Luiz Henrique Costa: "Não por acaso, até essa denominação frevo mais para frente, ela vai estar incluída nos jornais, também como uma referência de briga, de confusão e também no âmbito político. No meio político a palavra frevo às vezes era utilizada para se denominar alguma confusão, alguma briga, algum atrito entre partidos adversos ou entre políticos que tinham posicionamentos diferentes. No meio daquela confusão política intelectual, ao invés de dizer confusão, foi o maior frevo da Assembléia legislativa” (SANTOS, 2017).

Em outros seis cordéis o frevo estava relacionado a festa, porém em sentidos específicos (Baile, Celebração e Farra) com dois folhetos de cada sentido, que traz um novo olhar sobre essa palavra antes utilizada com sentido de bagunça, confusão ou atrito. Nessa perspectiva de ressignificação do termo frevo, Barbosa (2016, p. 65) diz que: Nas décadas de 1920 e 1930 , comumente reconhecidas como "era do rádio", o gênero passa a ser amplamente divulgado, adquire novas influências, moderniza-se, ganha suas subdivisões, consagra-se e, definitivamente é reconhecido pelo caráter nacional. Entende-se que nessa época nem todos tinham acesso ao rádio, mas como foi visto alguns poetas tinham um interesse peculiar pelas notícias e tentavam se manter informados.

Nessa travessia entre bagunça e gênero reconhecido nacionalmente e propagado pelas rádios, identificaram-se os outros quatro cordéis que registraram o frevo como Expressão Cultural, que está associado às manifestações estéticas da dança e da música, influenciados pela capoeira e expressões corporais dos trabalhadores, fanfarras e bandas militares.

Neste contexto, percebeu-se que a categoria Expressão cultural foi a mais recorrente no conjunto de folhetos de cordéis analisados. Laraia (2009, p. 68) define Cultura como "o modo de ver o mundo, as apreciações de ordem moral e valorativa, os diferentes comportamentos sociais e 


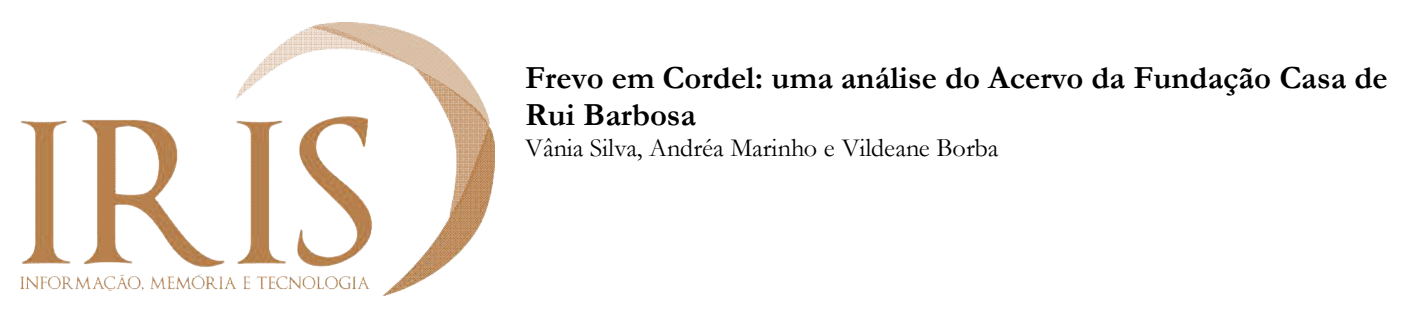

mesmo as posturas corporais são assim produtos de uma herança cultural, ou seja, o resultado da operação de uma determinada cultura".

Em consonância com Laraia (2009) entende-se que o termo cultura envolve vários aspectos de um povo, inclusive suas manifestações e expressões. Esta última aqui representada como a categoria mais recorrente que simboliza todas as atividades possíveis de exteriorização, isto é, manifestadas a partir das expressões como a Dança, a Ginga, a Malandragem, o Samba, a capoeira, a Música, o Passo, o Carnaval entre outros.

\section{Considerações finais}

Este artigo teve o objetivo de analisar o termo frevo em folhetos de cordéis, compreendendo o seu uso e significado e refletindo de que forma dialogam entre si. Os 14 folhetos de cordéis analisados retrataram o frevo como uma expressão cultural, assim como uma festa (Celebração, Farra e baile) e bagunça, estas apresentadas pela diversão, anarquia e confusão.

Percebe-se que o frevo está presente e representado nos folhetos de cordéis, especialmente por ser uma expressão cultural popular, refletindo o contexto sócio cultural e político de Pernambuco, tão bem retratados na literatura de cordel. As relações ao termo frevo nos folhetos de cordéis refletem os principais termos de significância encontradas nas categorias levantadas.

Este estudo é um recorte mínimo, diante do elevado acervo de folhetos de cordéis brasileiros existente porém, as dificuldades de busca e pesquisa em acervos desta natureza, impossibilitam um maior aprofundamento e análise, tornando-se uma limitação neste estudo.

Acredita-se que este trabalho contribui para a Ciência da Informação a partir das práticas culturais, compreendendo como os grupos sociais tecem seus saberes e, sobretudo, por meio da Ciência da Informação podemos comunicar e visualizar esse conhecimento, identificando, estudando e refletindo também sobre as fontes de informação marginalizadas.

\section{Referências}

ABREU, Márcia Azevedo de. Cordel Português/Folhetos nordestinos: confrontos, um estudo históriocomparativo. 1993. 360 f. Tese (Doutorado em Literatura Comparada) - Departamento de Teoria Literária, Instituto de Estudos da Linguagem, Universidade Estadual de Campinas, Campinas, 1993. 


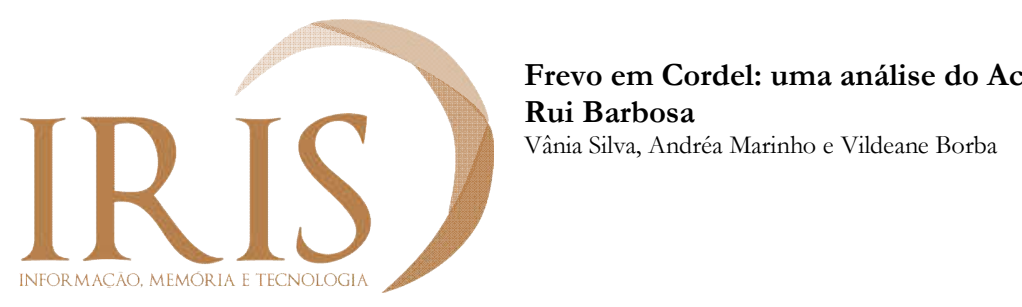

BARBOSA, Yêda (coord.). Frevo. Brasília: Iphan, 2016. Disponível em: http://portal.iphan.gov.br/uploads/ckfinder/arquivos/DossieIphan14_Frevo_web.pdf. Acesso em: 12 dez. 2019.

BARDIN, Lawrence. Análise de conteúdo. São Paulo: Edições 70, 2016.

CASCUDO, Luís da Câmara. Literatura oral no Brasil. 3.ed. São Paulo: Itatiaia; São Paulo: Universidade de São Paulo, 1984.

CASA DE NOCA. In: DICIONÁRIO Informal on line. @2006-2019. Disponível em: https://www.dicionarioinformal.com.br/casa+de+noca/. Acesso em: 10 dez. 2019.

FUNDAÇÃO CASA DE RUI BARBOSA. Literatura Popular em Verso da Fundação Casa de Rui Barbosa. [20-?]. Disponível em: http://www.casaruibarbosa.gov.br/cordel/apresentacao.html. Acesso em: 04 de abril de 2009.

CURRAN, Mark. História do Brasil em cordel. 2. ed. São Paulo: Ed. Edusp, 2001.

CURRAN, Mark. Retrato do Brasil em cordel. Cotia: Ateliê Editorial, 2011.

LARAIA. Roque B. Cultura: um Conceito Antropológico. 24. ed. Rio de Janeiro: Zahar, 2009.

LUYTEN, Joseph M. Feminismo versus machismo: autoras mulheres na literatura de cordel. [s.l.]: [s.n.], [200?]. Disponível em:

http://encipecom.metodista.br/mediawiki/images/8/88/Mulheres_autoras_de_cordel_.pdf. Acesso em: 27 abr. 2017.

MENEZES, H.; NASCIMENTO, L. (org.). Frevo Patrimônio Imaterial do Brasil: síntese do dossiê de candidatura. Recife: Fundação de Cultura da Cidade do Recife, 2011.

MICHEL, Maria Helena. Metodologia e Pesquisa Científica em Ciências Sociais. 2. ed. São Paulo: Atlas, 2009.

SANTOS, Luiz Henrique Costa dos. Frevo. [5 maio 2017]. Entrevistadores: Andréa Carla Melo Marinho e Vânia Ferreira da Silva. Recife: [S.n.], 2017. 1 HD (ca. 44 min.). Entrevista concedida à pesquisa.

SILVA, Mônica Pereira da. Frevo. [5 maio 2017]. Entrevistadores: Andréa Carla Melo Marinho e Vânia Ferreira da Silva. Recife: [S.n.], 2017. 1 HD (ca. 44 min.). Entrevista concedida à pesquisa.

Data de submissão: 01 de julho de 2019.

Data de aceitação: 26 de dezembro 2019.

\footnotetext{
${ }^{1}$ Disponível em: http://acervos.casaruibarbosa.gov.br.
} 